\title{
A cidade e as crianças na literatura para a infância. Um estudo exploratório a partir de três obras'
}

\author{
The City and Children in Children's Literature: \\ An Exploratory Study on Three Works
}

\author{
ÂNGELA BALÇA \\ CIEC. Universidad de Évora \\ FERNANDO AZEVEDO \\ CIEC, Universidade de Minho \\ Portugal \\ apb@uevora.pt \\ fraga@ie.uminho.pt
}

(Recibido: 05-O2-20I6; aceptado: $5_{5}^{-\mathrm{II}-2 \mathrm{OI} 6)}$

Resumo. $O$ artigo aborda o espaço físico e mental da cidade e a sua relação com as crianças em três obras de literatura para a infância. Partindo do entendimento de cidade apresentado por Ferreira (2015), Teixeira (2015) e Domingues (2015), o objetivo maior deste breve estudo é compreender que modelo de cidade é apresentado às crianças em obras de literatura para a infância escritas e ilustradas em diferentes décadas do século $X X I$, por artistas de diversas nacionalidades e editadas em diversos países. Para alcançar este objetivo faz-se uma leitura comparada, crítica e reflexiva destas obras. Como conclusão, podemos afirmar que o modelo/espaço cidade nestas obras de literatura infantil é apresentado como um território simultaneamente eufórico e disfórico, com matizes diversificados. Porém, à criança é sempre deixada uma palavra luminosa. Em todas as obras fica o apelo à comunicação, à partilha, à amizade.

Palavras - chave: literatura infantil; ilustração; cidade; partilha; comunicação.
Abstract. The article discusses the physical and mental space of the city, and its relationship with children, in three works of children's literature. Starting from the understanding of the city presented by Ferreira (2015), Teixeira (2015) and Domingues (20I5), the main objective of this short study is to understand what city model is presented to children in works of children's literature written and illustrated in different decades of the century, by artists of different nationalities, and edited in several countries. To accomplish this we carry out a comparative, critical and reflective reading of these works. In conclusion, we can say that the model / space of the city presented in these works of children's literature is simultaneously a euphoric and dysphoric territory, with diverse shades. However, for the child there always remains a word of light. In all works there is a call for communication, sharing, and friendship.

Keywords: children's literature; illustration; city; sharing; communication.

\footnotetext{
I Para citar este artículo: Balça, Ângela y Azevedo, Fernando (20I7). A cidade e as crianças na literatura infantil. Um estudo exploratório a partir de três obras. Alabe 15. [www.revistaalabe.com]

DOI: IO.I5645/Alabe20I7.I5.I
} 


\section{A cidade, espaço eufórico e disfórico}

Nos dias de hoje, os espaços urbanos representam um polo de atração para as pessoas, pelas oportunidades que eles oferecem. Porém, apesar de serem um lugar de inúmeras possibilidades, as cidades encerram igualmente um conjunto de problemas para as populações que as habitam. Simbolicamente, elas são espaços organizados com ruas e avenidas, com sentidos, com edifícios e seus habitantes. Nesta perspectiva, elas apresentam sempre um certo número de convenções, à luz das quais a vida é regida. Mas as cidades são também lugares de visibilidade e de invisibilidade, espaços onde os sonhos emergem e são destruídos, no fundo, um caleidoscópio de concretizações e de desejos. Historicamente, as cidades sempre estiveram ligadas a novas ideias, a novos avanços para a humanidade, ao cosmopolitismo. Desde há muito que vários campos do saber se interessam pelo estudo da urbe, nos seus mais diversos sectores, quer relacionados com a sua dimensão físico-territorial quer relacionados com a componente humana, cultural e ideológica.

De acordo com a ONU (2OI6), atualmente, $54 \%$ da população mundial vive em áreas urbanas e estima-se que aumente, em 2050, para 66\%, o que certamente leva Ferreira (20I5:I68) a afirmar que "(...) não é difícil antecipar que o modelo urbano será o grande referente - possivelmente o único - de toda a organização geográfica e social nas próximas décadas. A condição urbana é já a condição humana do século XXI”.

Ora muitas são as crianças e as suas famílias que vivem toda a sua vida nestes territórios urbanos, são elas que constituem o capital humano que faz mover e avançar as cidades, pois de acordo com Teixeira (20I5: 8) "Desde que Platão e Sócrates discutiam nos mercados atenienses, as razões que levam as cidades a triunfar têm mais a ver com o seu capital humano do que com as suas infraestruturas físicas.".

Na verdade, há um conjunto de fatores de ordem económica, social, psicológica, ambiental e cultural, elencados por diversos intelectuais, políticos e investigadores (Teixeira, 20I5; Ferreira, 20I5; Domingues, 20I5; Sampaio e Teixeira, 20I5) que se constituem como os grandes atrativos de uma cidade. Assim, nos espaços urbanos encontra-se a procura/oferta de uma maior diversidade de empregos e aí reside também a expetativa de uma promessa laboral mais desafiadora e mais recompensadora a nível pessoal e económico; é no espaço urbano que regra geral se exercitam novas sociabilidades, possibilitando simultaneamente a proximidade e o anonimato bem como a autonomia dos indivíduos. Os desafios culturais tornam os territórios urbanos como um chamariz, sobretudo para as gerações mais novas, que convivem diariamente e de modo democrático com a diversidade cultural. De facto, de acordo com Ferreira (20I5: I68) "De horizonte de expectativas a cidade tornou-se horizonte de projecção, que resiste a todas as desilusões, mesmo quando não consegue dar resposta às aspirações mais concretas e materiais."

Todavia, Teixeira (2OI5) e Domingues (2OI5) alertam para o lado menos positivo e menos atrativo dos espaços urbanos, afirmando que a urbanização é demasiadas vezes 
foco de pobreza, desigualdades, conflitos e injustiças, sendo um real desafio à governação. Muitas vezes aliados a estes focos estão os aspetos ambientais que marcam a cidade e exigem olhares, atitudes, medidas ousadas e integradas que permitem tornar mais habitável a "selva urbana". É neste contexto menos apelativo e numa tentativa de pensar a cidade que surge a obra de Francesco Tonucci (I997), que problematiza a relação entre as crianças e as cidades. Tonucci (r997) afirma que os cidadãos sofrem com os males da cidade e têm consciência que a cidade não é amigável para as crianças, pois "Saben que quienes más sufren son los niños, no saben cómo ayudarlos (...)” (Tonucci, I997:I7).

Deste modo, intelectuais, políticos, autarcas, investigadores confrontam-se com estas duas dimensões da cidade, espaço eufórico de todas as possibilidades, mas também espaço disfórico de pobreza e de desigualdade. E estes serão grandes desafios que se colocam ao capital humano que faz mover as cidades, muitas vezes pressentidas como potenciadoras da desumanização, da incomunicabilidade, da solidão, pouco amigas do desenvolvimento das relações humanas, necessárias para uma vida harmoniosa e cidadã.

\section{A cidade e as crianças na Literatura para a infância}

A cidade e as temáticas com ela relacionadas, nomeadamente a interação entre/ com a criança e a cidade, marcam presença nas obras de literatura para a infância. Em várias obras de literatura para a infância encontramos ecos ou mesmo representações da cidade, que podem ser mais ou menos explícitas e que estão presentes quer no texto verbal quer no texto icónico. A literatura para a infância, embora obedecendo ao protocolo da ficcionalidade, ajuda a criança a familiarizar-se com o mundo e veicula para os mais novos conhecimentos e valores que os auxiliam a pensar e a interrogar esse mesmo mundo (Sloan, I99I; Azevedo, 2OII). Além disso, instaurando a palavra, a memória da humanidade, a literatura torna-se formativa, crítica e criadora. Graças a ela, os mais novos podem partilhar saberes e experiências humanas, intelectual e culturalmente estimuladoras, nutrindo as raízes para a criação de hábitos de interação cultural fruitivos e passíveis de se expandirem ao longo da vida.

Os textos de literatura para a infância, verbais e plásticos, apresentam determinado(s) modelo(s) de cidade, prontos a ser observados, compreendidos ou mesmo desconstruídos pelas crianças. Assim, neste estudo centramo-nos no modo como a literatura infantil representa o território, sobretudo o urbano ou pressentido como tal, e a inserção/ relação das crianças com a cultura e modo de vida desse mesmo espaço.

Esta matriz literária tem trazido a lume várias obras que mostram às crianças diversos contextos que influenciam de forma muito clara as relações sociais, familiares e afetivas que podem ou não estabelecer-se nesse território.

Deste modo, este estudo tem como objetivos compreender que modelo(s) de cidade são representados e apresentados às crianças nos textos de literatura para a infância; perceber se os textos de literatura para a infância, escritos e ilustrados em diferentes 
décadas do século XXI, representam a cidade do mesmo modo; compreender se os textos de literatura para a infância, escritos e ilustrados por artistas de diversas nacionalidades, encerram modelos diferentes de cidade.

Para efetivarmos este estudo, socorremo-nos das seguintes obras: Vizinho, Vizinha, dos brasileiros Graça Lima, Mariana Massarani e Roger Mello, publicada pela editora Companhia das Letrinhas no ano de 2002; Perto, da argentina Natalia Colombo, editada pela editora Kalandraka, em 2008; e por fim Amigos do peito, do brasileiro Cláudio Thebas e da espanhola Violeta Lópiz, vinda a lume na editora Bruaá, em 2OI4.

Lançada em 2002, pela editora brasileira Companhia das Letrinhas, a obra Vizinho, Vizinha apresenta uma tripla autoria dos premiadíssimos brasileiros Roger Mello (vencedor do Prémio Hans Christian Andersen, em 20I4), Mariana Massarani e Graça Lima. Esta tripla autoria reflete-se na estrutura da própria obra, sobretudo nas personagens e nos espaços. Assim, Roger Mello é o autor do texto verbal e do texto plástico espaço corredor do prédio; Mariana Massarani é a ilustradora da personagem Vizinho e da sua casa; a Graça Lima coube as ilustrações da personagem Vizinha e do seu lar.

Dominado por cores fortes, o texto plástico desta obra aposta sobretudo em dois tons: o cor-de-rosa e o amarelo. A temática da cidade pode ser logo pressentida nos paratextos capa e contracapa que formam um díptico, mas também nas guardas do livro que, a preto e branco, fazendo lembrar uma maquete, nos presenteiam com o espaço de uma cidade.

Vizinho, Vizinha é, na sua estrutura, uma obra extraordinariamente original. Em termos plásticos, a obra divide-se fisicamente em três partes: a casa do Vizinho, a casa da Vizinha e o corredor do prédio; quanto à palavra escrita, ela encontra-se justaposta ao Vizinho e à Vizinha, o que não significa que não se refira ao corredor. Muito interessantes são os aspetos plásticos ligados à palavra escrita - para o Vizinho surge o cor-de-rosa forte; para a Vizinha o amarelão, o que num livro para os mais novos pode ser significativo, uma vez que contraria os estereótipos de género normalmente associados ao cor-de-rosa.

O início da obra situa imediatamente o leitor mais novo no espaço onde se irá desenrolar a intriga "Quem passa pela Rua do Desassossego, número 38, nem percebe, mas...", deixando estas reticências um vasto campo de hipóteses interpretativas a explorar. E a obra continua com a história de um Vizinho e de uma Vizinha que vivem no mesmo prédio, no mesmo andar, em casas em frente uma da outra, apenas separadas por um corredor. Com gostos e manias diferentes, estes vizinhos vivem a sua vida, dentro das suas casas, de forma isolada. Mal se conhecem e só se encontram no espaço neutro, que é o corredor, sempre na mesma hora: "Quatro e quarenta: ele sai com o canário para um passeio. Vinte para as cinco: ela finalmente leva o relógio ao conserto. Só se encontram a esta hora.”. E é no corredor, aparentemente um espaço independente e imparcial, que nada tem a ver com eles ou com as suas distintas casas, que o Vizinho e a Vizinha trocam um sorriso e umas breves palavras "No corredor: Boa tarde, boa tarde, como tem passado? Como está o tempo? E é só.” 
Até aqui, esta obra situa-nos num mundo que facilmente colamos à cidade e ao modo de vida que nela parece imperar. Individualismo, anonimato, relações ténues e precárias parecem ser cultivadas com gosto pelos protagonistas desta história e pelos habitantes da cidade em geral.

Todavia, nesta história, algo de inesperado acontece. O Vizinho "tem uma Sobrinha quase da idade do neto dela." e a Vizinha "tem um Neto dois dedos menor que a sobrinha dele." que coincidentemente os visitam no mesmo dia. Na ausência dos adultos, as duas crianças abrem as portas de casa para o corredor, "A Sobrinha espreita." e "O Neto observa." Após este primeiro momento de contacto visual, o corredor que era um espaço neutro, independente, imparcial tornou-se num prolongamento das duas casas que se uniram através desta área.

Após o fim da visita das crianças aos respetivos familiares, “(...) o silêncio ensaiou meia dúzia de passos de dança.”. O Vizinho e a Vizinha voltam às suas velhas rotinas. Porém, o texto plástico alarga este episódio. Se antes da visita das crianças, os protagonistas estavam felizes e satisfeitos, com uma atitude positiva e um sorriso no rosto, depois da visita das crianças ambos parecem deprimidos e entristecidos. Os dois estão agora dispostos a conhecerem-se melhor "Qualquer dia desses ele convida a Vizinha para entrar. Se ele convidar, ela aceita." Na ilustração, à porta de entrada da casa da Vizinha, os múltiplos tapetes que desfilam ao longo da história são agora substituídos por um outro que diz "Bem-Vindo".

Deste modo, notamos uma evolução nesta obra, no que diz respeito à atitude das personagens. Da indiferença, da incomunicabilidade pressente-se que pode vir a ser construído e a existir um caminho para a comunicação e para a relação, percurso esse consentido simbolicamente pelas crianças, pela sua abertura, pela sua curiosidade, pela sua capacidade de relacionamento.

A obra Perto, lançada em 2008 pela editora espanhola Kalandraka, é da autoria de Natalia Colombo. Nascida na Argentina, Natalia Colombo ganhou com Perto o I Prémio Internacional Compostela para Álbuns Ilustrados 2008.

Nesta obra, aparentemente marcada pela simplicidade, encontramos ecos da cidade, o espaço urbano é adivinhado tanto nas ilustrações como no texto verbal. Na verdade, o espaço ilustrado apresenta marcas de urbanidade: casas que se assemelham a prédios, jardins e estradas onde se cruzam meios de transporte como carros ou bicicletas. No texto verbal, são expressões como "com muita pressa", "praça", "parque" que nos permitem colocar a hipótese interpretativa da intriga se centrar em território citadino.

Marcada por um curtíssimo mas poético, tocante e significativo texto verbal e por belíssimas ilustrações que dialogam, entretecem e acrescentam consideravelmente a palavra escrita, Perto apresenta uma estrutura paralelística. Este paralelismo é sentido nas personagens (o Senhor Pato e o Senhor Coelho), nos espaços, no tempo, nas ações. O Senhor Pato e o Senhor Coelho fazem exatamente as mesmas coisas, nos mesmos espaços, no mesmo tempo “(...) cruzam-se sempre. Quando vão...e quando vêm.”. 
Os paratextos desta obra, nomeadamente a capa e a página de rosto, podem levar o pequeno leitor a levantar uma hipótese interpretativa que de facto não se irá confirmar. Em ambos os paratextos, surge-nos um coelho e um pato, de frente um para o outro, o que poderá indiciar que são conhecidos ou mesmo amigos. Na verdade, ao longo da obra, vai-se desenhando uma metáfora dos tempos modernos, muito comum nos espaços urbanos. Apesar de se cruzarem todos os dias, nos mais diversos lugares e nas mais variadas horas do dia, com os mais distintos estados de alma, o Senhor Pato e o Senhor Coelho "nunca se cumprimentam". O texto icónico alarga a leitura do texto verbal e mostra-nos um Senhor Pato e um Senhor Coelho com ar infeliz, abatido, quase sempre de costas voltadas um para o outro.

Deste modo Perto encerra uma realidade onde impera a falta de comunicação, a solidão, a falta de partilha e de entreajuda, uma sociedade marcada pelo isolamento, pela incomunicabilidade, pelo individualismo. Esta é uma realidade consistente com as grandes urbes, palcos de "tantas incompreensões, formigueiros de anseios contraditórios" (Teixeira, 20I5, p. II).

Todavia, esta obra constitui-se igualmente como um alerta, se tivermos em conta o seu desenlace. O Senhor Pato e o Senhor Coelho deixam escapar a oportunidade do encontro e o narrador posiciona-se "É realmente uma pena... Poderiam ser grandes amigos.", revelando o texto icónico os inúmeros momentos de convívio e de partilha que poderiam ter acontecido entre os dois.

Fica este despertar de consciências, para a abertura ao Outro, tão cara à própria Natalia Colombo "En el momento en que termino un proyecto, lo que más me motiva es la posibilidad de llegar a las manos de un niño o de un adulto. Que se apropien de él; de esa posibilidad de poder contarles cómo es mi mundo, cómo me imagino personajes e historias." (http://www.imaginaria.com.ar/2009/ro/natalia-colombo/).

Assinada pelo brasileiro Cláudio Thebas e ilustrada pela espanhola Violeta Lópiz, a obra Amigos do Peito veio a lume pela mão da portuguesa Editora Bruaá, no ano de 2OI4. Violeta Lópiz conquistou com as ilustrações desta obra o Prémio Ilustrate 2016.

Nesta obra, o espaço urbano é bem visível no texto plástico. Estas ilustrações foram concebidas em Lisboa, cidade para onde a ilustradora se mudou, quando foi convidada pela Editora Bruaá a ilustrar o texto de Cláudio Thebas "Lo primero que hice esta vez para reiniciar mi cabeza fue, mudarme a Lisboa (...). Llegamos el 5 de Enero de 20I4.” (http://violetalopiz.blogspot.pt/). E, na verdade, um olhar atento às instigantes ilustrações de Violeta Lópiz revela-nos uma cidade cosmopolita, igual a tantas outras; mas Lisboa pode ser pressentida, com as suas marcas: a calçada portuguesa, os miradouros e os seus quiosques, as escadinhas íngremes dos bairros históricos. Portanto, paratextos como capa e contracapa (que formam neste caso um díptico), guardas e página de rosto permitem praticamente sem reservas que o leitor mais novo levante a hipótese interpretativa de que esta obra encerrará alguma história que se passa ou que se relaciona com a cidade. 
A belíssima prosa poética, assinada por Cláudio Thebas, encerra uma ilusória singeleza. Aliás, socorremo-nos de novo das palavras da ilustradora Violeta Lópiz, para atestarmos a complexidade que encerra o texto,

Lo segundo que hice fue leer el poema muchas veces y entender que no era en absoluto un texto sencillo, pues no me daba casi pistas, y además no tenía una trama narrativa clara. (...) La mitad del tiempo lo dediqué a descifrar qué me decía el texto de Claudio (...).(http:// violetalopiz.blogspot.pt/).

Assim, Cláudio Thebas assina um texto cuja temática lhe é muito querida - a cidade, as ruas, as praças e os parques, "Desejo de encontrar pessoas, conhecer suas culturas e expressões. Sonhos se realizam. (...) concretizando mais uma vez o sonho de promover encontros essencialmente humanos com as cidades, suas pessoas, seus artistas." (http:// claudiothebas.com.br/tomaraquide.html) É esta visão da cidade, como local de encontro, conhecimento, sonho, inovação, criação, partilha que nos é também transmitida por Ferreira (20I5: I68), "As novas cidades são hoje lugares de convergência e afirmação de aspirações culturais novas, de novas formulações do desejo, de novas formas de procurar a alegria e o prazer, de partilhar a informação, de criar."

A obra Amigos do peito encerra, deste modo, um texto que nos fala do bairro, da rua ("Transformando a rua, não transformamos a cidade?" pergunta retoricamente Cláudio Thebas - http://claudiothebas.com.br/tomaraquide.html) e a palavra escrita é enormemente alargada pelas ilustrações que extravasam a rua, o bairro e nos situam na cidade.

Esta obra aborda, numa leitura mais de superfície, a vida na cidade, dando desta vida uma imagem muito positiva. Viver na cidade, neste caso em particular num determinado bairro ou mesmo numa certa rua, é neste texto sinónimo de convívio entre as crianças que nele/a habitam. E, assim, os amigos do protagonista, uma criança em idade escolar, "Todos os dias regresso da escola", que surge em todas as ilustrações com calças vermelhas, blusa castanha, cabelo encaracolado negro, mochila azul às costas, acompanhada de um gato preto, são crianças que vivem perto umas das outras e que partilham os mesmos espaços/equipamentos das redondezas - a esquina, o lado, o prédio da frente, o sétimo andar, o bar - dando voz a uma centralidade, assinalada pelos equipamentos escola e bar, que marca a organização de muitos dos atuais espaços urbanos. De facto, a criança protagonista volta quotidianamente da escola com "a Ana Lúcia da esquina"; refere "o Carlos Alberto, do lado" e o facto de ele não emprestar a bicicleta a ninguém; menciona como seus amigos “o Bruno do prédio da frente, o Ricardo do sétimo andar, o irmão da Lúcia da esquina, o filho do dono do bar.”

O conhecimento, o convívio, a amizade estabelecida entre o protagonista e todas estas crianças é extraordinariamente marcada pelos espaços do bairro/rua, onde todos/ as habitam, estudam, brincam, contactam. E este traço é revelado pelo facto da criança protagonista não saber os nomes completos dos seus amigos "O nome completo deles eu nunca sei, ou esqueço.”, nem mesmo os seus apelidos, “(...) Ana Lúcia da esquina. Da 
esquina não é apelido é o endereço da menina.”; "Já o Carlos Alberto, do lado, (do lado não é nome também)", porque "Amigo não tem apelido: amigo tem endereço.". Ora as palavras finais do texto de Cláudio Thebas mostram que "um monte de amigos do peito" são parte intrínseca do bairro/rua, são como que a sua extensão, unindo-se e confundindo-se numa ligação inequívoca e profunda com a cidade. A rua, o bairro, a cidade são muito mais que o local onde estas crianças caminham, brincam, jogam à bola, andam de bicicleta; são um espaço que se entrelaça nas suas vidas.

Voltando às palavras de Violeta Lópiz, "Aunque me daba un poco de miedo, decidí alejarme del texto e ilustrar aquello que yo sentía sobre la amistad. Dejaría que las imágenes contrastaran con el texto pero que hablaran de la misma cosa.” (http://violetalopiz.blogspot.pt/), notamos a sua necessidade de estender o texto de Cláudio Thebas. E neste alargamento das ilustrações em relação à palavra escrita encontramos a cidade, no seu espaço físico "la arquitectura y la cartografía, coleccioné casas, tejados, chimeneas, azulejos, tiendas, muros, ventanas, plazas, mercados y rutas.” (http://violetalopiz. blogspot.pt/), mas igualmente a cidade, no seu espaço mental e relacional "explorar la relación entre lugares y personas, arquitectura y sentimientos, mapas mentales, lugares en el cuerpo, en la mente, en la calle, la memoria que viven en los lugares y los lugares que viven en la memoria.” (http://violetalopiz.blogspot.pt/), aquele espaço que subjaz, inspira e pelo qual luta Cláudio Thebas, no seu multifacetado trabalho.

Deste modo, as ilustrações mostram-nos ainda uma outra parte da história, centrada na página de rosto e nas duas últimas páginas da obra. Esta narrativa visual segue o percurso da criança protagonista, saindo do seu prédio, caminhando e usufruindo dos vários espaços da cidade e chegando, de novo, ao seu prédio. À saída de casa, os seus amigos espreitam à esquina do prédio; ao regressar a casa, espera-o uma festa surpresa, preparada pelos seus companheiros.

Ora Amigos do Peito constitui-se na realidade como uma obra que nos propõe inúmeras hipóteses interpretativas e múltiplas leituras da realidade. Numa leitura mais profunda desta tessitura verbal e plástica, ressaltam o cultivar das relações humanas, da amizade, da partilha que as crianças ainda conseguem, num espaço que tantos consideram adverso ao estabelecer e aprofundar destes valores.

\section{Considerações finais}

Neste breve estudo debruçámo-nos sobre o espaço cidade, como um território eufórico e disfórico. Com uma percentagem muito elevada da população mundial a viver em territórios urbanos, a cidade toma várias qualidades. Se para alguns investigadores e intelectuais, ela é sinónimo de novas oportunidades, novas sociabilidades, sempre renovados desafios culturais, para outros ela representa um enorme repto à governação. Este repto ao governo da cidade é lançado não só pelos aspetos eufóricos que ela encerra, mas sobretudo pelos aspetos disfóricos, caracterizados pela pobreza, pela desigualdade, pela 
não aceitação do Outro, pelo individualismo, pela solidão, marcas tão presentes em tantos espaços urbanos,

Hoje diz-se (e pensa-se) que estamos num mundo onde a maioria das pessoas vive em cidades, pensando dessa maneira num mundo mais justo ou mais emancipado e "moderno". A verdade é que essa afirmação contém outra bem menos positiva: a urbanização do planeta é, na sua maioria, a urbanização da pobreza (...) (Domingues, 2OI5: 22).

A literatura para a infância encerra um conjunto de textos que nos trazem ecos ou mesmo representações dos territórios urbanos. Esta matriz literária tem presenteado os leitores mais novos com textos de grande qualidade literária e plástica, onde se apresentam distintos modelos de cidade mas também diversas relações que se podem estabelecer entre os espaços urbanos e os indivíduos, nomeadamente as crianças. Estas obras de literatura para a infância concorrem, certamente, para que as crianças possam ler o mundo de forma plural e estabelecer pontos de contacto entre a sua realidade e o mundo presente nesses textos.

Neste estudo nortearam-nos os objetivos de compreender que modelo(s) de cidade são representados e apresentados às crianças nos textos de literatura para a infância e perceber se, por um lado, os textos de literatura para a infância, escritos e ilustrados em diferentes décadas do século XXI e, por outro lado, escritos e ilustrados por artistas de diversas nacionalidades, representam a cidade do mesmo modo e encerram modelos diferentes de cidade. Para o cumprimento destes objetivos socorremo-nos de obras escritas, ilustradas e mesmo editadas em vários pontos do globo na I. ${ }^{\mathrm{a}}$ e $2 .{ }^{\mathrm{a}}$ década do século XXI.

Deste modo, pudemos perceber que nas três obras que estudámos encontramos perspetivas distintas ao encarar a cidade e as relações que os indivíduos estabelecem ou não nestes territórios.

A obra Perto, de Natalia Colombo, mostra-nos a cidade como um local onde impera a solidão e a incomunicabilidade. As personagens, muito embora se cruzem todos os dias e tenham os mesmos hábitos, nunca têm espaço/tempo/vontade para o encontro. Porém, a obra encerra uma mensagem de esperança para os leitores mais novos, deixada pelo narrador, que faz um apelo à comunicação, à partilha, ao conhecimento mútuo, ponto de partida para a amizade.

A obra Vizinho, Vizinha, de Roger Mello, Mariana Massarani e Graça Lima, é de certo modo uma obra onde a cidade é encarada como um espaço de confiança. As personagens comunicam, trocam algumas impressões entre si, muito embora não se conheçam realmente, mesmo vivendo no mesmo prédio, em casas uma em frente da outra. A mensagem de esperança é aqui deixada pelas personagens crianças, familiares do Vizinho e da Vizinha. São elas que quebram a distância física entre as duas casas, ocupando o espaço do corredor e invadindo ambas as habitações; são elas que deixam a expetativa, o desejo nos adultos de se conhecerem melhor. 
A obra Amigos do Peito, de Cláudio Thebas e Violeta Lópiz, apresenta-nos a cidade como um lugar de comunhão e partilha. Texto plástico e palavra escrita mostram uma criança protagonista que vive em harmonia na e com a cidade, onde estuda, brinca, convive com os seus amigos. Nesta obra a cidade é humanizada, crianças e bairro onde habitam confundem-se no quotidiano, indo ao encontro das vivências de muitas crianças e deixando aqui uma mensagem de esperança às gerações mais novas.

Deste modo, podemos afirmar que vários modelos de cidade e da relação que os seus habitantes estabelecem com esse espaço surgem nestas obras. Escritas e ilustradas por autores de várias nacionalidades, escritas e ilustradas em datas diferentes, editadas em distintos países, pensamos que todas elas deixam às crianças uma palavra luminosa. Em todas as obras fica o apelo para a comunicação, para a partilha, para a amizade, para o convívio, como que dizendo que é possível caminharmos para um modelo de cidade como um espaço eufórico, onde viver na plenitude é possível e que o embaixador Francisco Seixas da Costa (20I5: I66) enuncia da seguinte forma: "As cidades só existem connosco dentro. (...) A cidade ideal é aquela onde se é feliz. E isso está dentro de nós, a cidade é apenas o lugar onde encenamos a vida.”. 


\section{Referèncias bibliográficas}

- Azevedo, F. (20II). Formar leitores capazes de ler o mundo desde uma idade precoce. Os lugares da literatura infantil e juvenil na sociedade contemporânea. In J. A. Silva, J. C. Martins e M. Gonçalves (Eds.), Pensar a Literatura no Séc. XXI (pp. 27-278). Braga: Universidade Católica Portuguesa.

- Costa, F. S. (20I5) Os cenários da vida. XXI. Ter Opinião. Isto é Cidade, 4, I66.

- Domingues, A. (2015) Cidade esponja. XXI. Ter Opinião. Isto é Cidade, 4, I8-3I.

- Ferreira, A. M. (20I5) O factor humano. XXI. Ter Opinião. Isto é Cidade, 4, I68.

- ONU. (20I6) Centro Regional de Informações das Nações Unidas. Obtido I9 de janeiro de 20I6 desde http://www.unric.org/pt/actualidade/3I537-relatorio-da-onu-mostra-populacao-mundial-cada-vez-mais-urbanizada-mais-de-metade-vive-em-zonas-urbanizadas-aoque-se-podem-juntar-25-mil-milhoes-em-205O

- Sampaio, J. \& Teixeira, A. J. (2015) Mais descentralização. XXI. Ter Opinião. Isto é Cidade, 4, IO8-III

- Sloan, G. D. (199I). The Child as Critic. Teaching Literature in Elementary and Middle Schools. New York-London: Teachers College Press/Columbia University.

- Teixeira, A. J. (20I5) Mais poder para as cidades. XXI. Ter Opinião. Isto é Cidade, 4, 8-II.

- Tonucci, F. (1997). La ciudad de los niños. Un modo nuevo de pensar la ciudad. Madrid: Fundación Germán Sánchez Ruipérez 